\title{
Screening of Raw Milk Samples of Cow for Tetracycline Residues using Chromatographic Technique
}

\author{
Rajkishor Gogoi $^{1^{*}}$ and D.C. Roy ${ }^{2}$ \\ ${ }^{1}$ Department of Veterinary Pharmacology and Toxicology, Apollo College of Veterinary \\ Medicine, Jaipur, Rajasthan, India \\ ${ }^{2}$ Department of Pharmacology and Toxicology, College of Veterinary Science, \\ Guwahati, Assam, India \\ *Corresponding author
}

\begin{abstract}
A B S T R A C T
\section{Keywords}

Milk, Residues, Tetracyclines, Ultra high performance liquid chromatography

Article Info

Accepted:

12 March 2019

Available Online:

10 April 2019

Antibiotics are freely used as growth promoters and for treatment of animal diseases without adequate knowledge. The indiscriminate use of antibiotics pose a considerable risk due to the presence of residues in milk meant for human consumption. A study was conducted for collection of raw milk samples and its screening for Tetracycline residues using Ultra High Performance Liquid Chromatography (UHPLC) system coupled to Diode Array Detector (DAD). About 175 raw milk samples of cow were randomly collected from roadside milk vendors in sterile containers and then preserved until analysis. Homogenization and ultrasonication of milk samples were performed followed by ultracentrifugation, extraction and filtration by using $0.2 \mu \mathrm{m}$ syringe filter. The Standard calibration curves of Oxytetracycline and Tetracycline showed good linearity. Oxytetracycline residue was detected in two milk samples of Cow with concentration of $0.146 \mu \mathrm{g} / \mathrm{g}$ and $0.181 \mu \mathrm{g} / \mathrm{g}$. Both the samples were above the permissible limit. Also, three samples of Cow milk were detected with residues of Tetracycline with level of $0.083 \mu \mathrm{g} / \mathrm{g}$, $0.114 \mu \mathrm{g} / \mathrm{g}$ and $0.125 \mu \mathrm{g} / \mathrm{g}$. Out of the 3 samples, 2 samples were found to be above the MRL.
\end{abstract}

\section{Introduction}

Antibiotics and antibacterial agents such Oxytetracycline (OTC) and Tetracycline (TC) are widely used in dairy farms. They are administered to animals not only for prevention and treatment of diseases, but also for fraudulent growth promotion. In dairy animals tetracyclines may be administered orally, parenterally or through intramammary infusion ${ }^{[1]}$. Tetracyclines may persist in the body long after their administration due to enterohepatic circulation. Improper use of these agents may result as residues in milk, which can be toxic and dangerous for human health potentially causing adverse reactions. The long-term presence of tetracycline residues may cause antibiotic resistance ${ }^{[2]}$. The wide applications of tetracyclines have led to the equally fast spread of tetracycline resistant strains of gram-positive and gramnegative bacteria, including strains belonging 
to pathogenic as well as non-pathogenic species. Non-pathogenic bacteria could act as a reservoir of resistance determinants, which can be disseminated by horizontal transfer into pathogens. More than thirty different tetracycline resistance genes have been characterized ${ }^{[3]}$. Super infections may occur with many antibiotics and especially as observed in case of tetracyclines.

The bacteria that colonize various sites are noted to be tetracycline resistant. Hence another antibiotic needs to be selected to combat tetracycline induced infections. The therapeutic use of antibiotics generally involves higher doses of antibiotics for relatively short period whereas prophylactic use involves moderate dose of antibiotic treatment of animals to an extended period of time.

To assure consumer's safety and high quality dairy products, raw milk must be regularly screened for the presence of drug residues. Detecting violative levels of antibiotic drug residues in milk through the use of residue screening and other qualitative tests can help prevent contaminated milk from entering the human food chain. The Codex Alimentarius Commission (2012) has established Maximum Residue limit (MRL) of $0.1 \mu \mathrm{g} / \mathrm{g}$ for tetracycline residues in milk. Several methods including UV- spectrophotometry and chromatography have been used for the monitoring of tetracyclines in food of animal origin using complex clean up procedure ${ }^{[4,5]}$. Jevinova et al., (2003) determined the residues of OTC in milk samples of cow using microbial inhibition assays [6] Navratilova et al., (2009) determined the residues of tetracyclines in raw milk of cow using milk tetra sensor kit ${ }^{[7]}$. Bilandzic et al., (2011) reported an Immunoassay method for determination of residues of tetracyclines and few antibiotics in raw milk samples ${ }^{[8]}$.
Thus the present study was conducted for collection of raw milk samples and its screening for Tetracycline residues using Ultra High Performance Liquid Chromatography (UHPLC) system coupled to Diode Array Detector (DAD).

\section{Materials and Methods}

\section{Sample collection}

About 175 raw milk samples of Cow $(100 \mathrm{ml})$ were collected from roadside milk vendors (Table 1). The samples were randomly collected throughout the year in sterile sample containers. The samples were labelled and transported to the laboratory in thermo-cooled containers jacketed with ice and stored till the time of analysis of the samples.

\section{Chemical and reagents}

Oxytetracycline standard (Sigma), Tetracycline standard (Sigma), Acetonitrile HPLC grade (Merck), Methanol HPLC grade (Merck), Water HPLC grade, chemicals and solvents of analytical grade were used for the study.

\section{Apparatus}

The UHPLC system (Dionex, Germany) equipped with auto-sampler, quaternary pump and Diode Array Detector (DAD) was used. The analytical column was reversed-phase $\mathrm{C}_{18}, 25 \mathrm{~cm} \times 4.6 \mathrm{~mm}$ I.D., $5 \mathrm{~m}$ column. Refrigerated centrifuge machine (Sigma), ultrasonicator (Sartorius) and homogenizer (IKA) were used for sample preparation.

\section{Standard solutions}

Stock standard solution of Oxytetracycline and tetracycline compound was prepared by dissolving $10 \mathrm{mg}$ of the compound in $10 \mathrm{ml}$ of methanol to obtain a final concentration of 1 
$\mathrm{mg} / \mathrm{ml}$. Stock standard solutions were put in amber glass to prevent the photo-degradation. Further dilutions were made from this solution in methanol in the descending concentration of 5.0,4.0,3.0, 2.0 and 1.0 $\mu \mathrm{g} / \mathrm{ml}$ respectively.

\section{Fortification of samples}

The milk samples were spiked with known concentrations of OTC and TC. Fortified samples were allowed to stand at $4{ }^{\circ} \mathrm{C}$ for $1 \mathrm{~h}$ before analysis.

\section{Extraction and clean up procedure}

About $10 \mathrm{ml}$ of the milk sample was taken in a $50 \mathrm{ml}$ centrifuge tube. To it added $10 \mathrm{ml}$ of 0.1 M EDTA-McIIvaine buffer ( $\mathrm{pH}$ 4.0) followed by vigorous shaking for 5 mins. The sample was then centrifuge at $6000 \mathrm{rpm}$ for 10 mins. The supernatant was collected and filtered through a Whatman filter paper No. 42. Clean up of the extract was done by using Solid Phase Extraction (SPE) method. The filtrate was loaded on a Sep-pak $\mathrm{C}_{18}$ cartridge preconditioned with $3 \mathrm{ml}$ of methanol and 2 $\mathrm{ml}$ of water. The cartridge containing the sample was washed with $5 \mathrm{ml}$ of water and then tetracyclines were eluted with $4.5 \mathrm{ml}$ of 0.01M Methanolic oxalic acid. The extract so obtained was filtered through a syringe filter $(0.2 \mu \mathrm{m})$. Later, $20 \mu \mathrm{l}$ of the eluted sample was injected into the UHPLC system for analysis.

\section{Chromatographic condition}

A mobile phase of $0.01 \mathrm{M}$ oxalic acid: Acetonitrile: Methanol (77: 18: 5, v/v/v) was used. The flow rate was kept at $1.0 \mathrm{ml} / \mathrm{min}$ keeping mode as isocratic.

\section{Detection and quantification}

The separated TCs were detected with DAD and quantification by Chromeleon chromatographic software interfaced to a personal computer. The wavelength for the detector was set at $350 \mathrm{~nm}$. A standard calibration curve with coefficient of determination of $99.50 \%$ was obtained by plotting concentration against the peak areas obtained (Figure 1). A standard calibration curve with coefficient of determination of 99.05 \% was obtained by plotting concentration against averages of the peak areas obtained (Figure 2).

\section{Results and Discussion}

An extraction step with a suitable solvent system along with clean up procedure was followed for detection and quantification of tetracycline residues. Since it is difficult to extract tetracyclines from biological matrix through organic solvent so extraction technique involves McIIvaine buffer for protein precipitation. Solid phase extraction clean up step is required to isolate TCs from interference of a complex sample matrix prior to the chromatographic analysis. Separation of TC residues isolated from biological matrixes was performed on a reverse phase $\mathrm{C}_{18}$ column using mobile phase by isocratic elution. In multi-residue analysis of $\mathrm{TC}$ in food, HPLC with UV detectors were the most commonly used one because they are more readily available and convenient to use in labs ${ }^{[9]}$. In the present study, TCs were separated on the $\mathrm{RP}-\mathrm{C}_{18}$ column using DAD which offers typically a wider scanning range of 350-365. It was found that the detector response factor at $350 \mathrm{~nm}$ was optimum for detection of wavelength for TCs. The separation and peak shapes of TCs standards were better using the present mobile phase (0.01 M oxalic acid, Acetonitrile, Methanol; 77: $18: 5 \mathrm{v} / \mathrm{v} / \mathrm{v})$. The flow rate was kept at 1.0 $\mathrm{ml} / \mathrm{min}$ keeping mode as isocratic. Linearity was evaluated by calibration in the range of 1.0 to $5.0 \mu \mathrm{g}$ for each compound at five points with triplicate analysis (Fig. 3 and 4). 
Table.1 Cow milk samples collected from different places of Assam

\begin{tabular}{|l|c|}
\hline $\begin{array}{c}\text { Places of } \\
\text { collection }\end{array}$ & Total \\
\hline Guwahati & 50 \\
\hline Nalbari & 15 \\
\hline Barpeta & 20 \\
\hline Golaghat & 12 \\
\hline Jorhat & 20 \\
\hline Sibsagar & 16 \\
\hline Dibrugarh & 20 \\
\hline Dhemaji & 12 \\
\hline Lakhimpur & 10 \\
\hline \multicolumn{1}{|c|}{ TOTAL } & $\mathbf{1 7 5}$ \\
\hline
\end{tabular}

Fig.1 Standard curve of oxytetracycline (OTC)

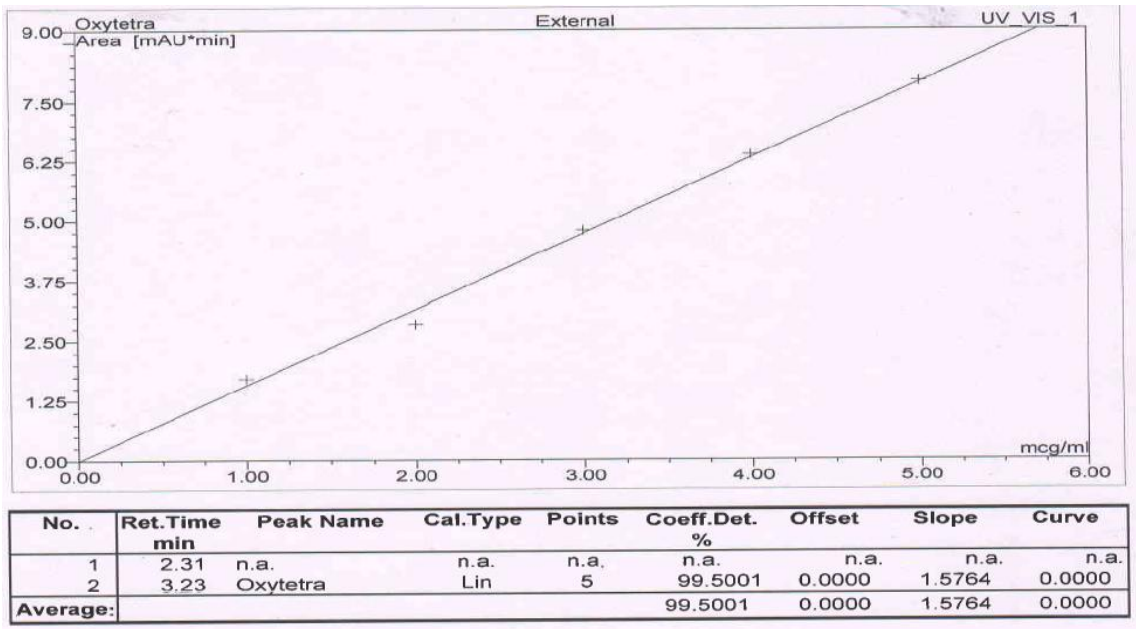

Fig.2 Standard curve of tetracycline (TC)

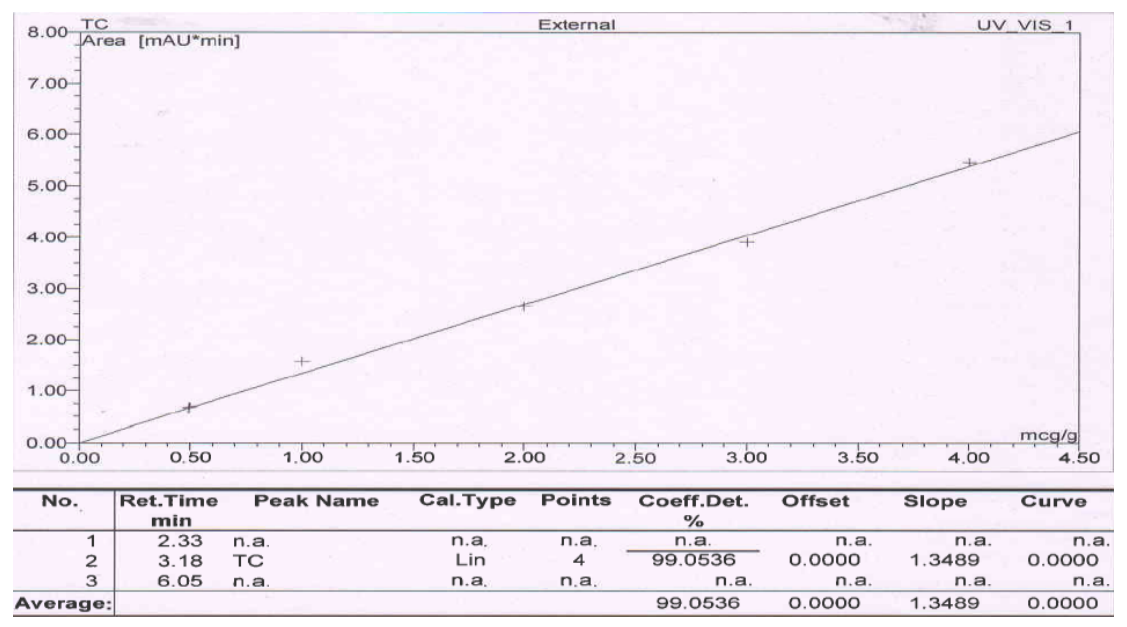


Fig.3 Chromatogram of milk sample of cow detected with OTC residue

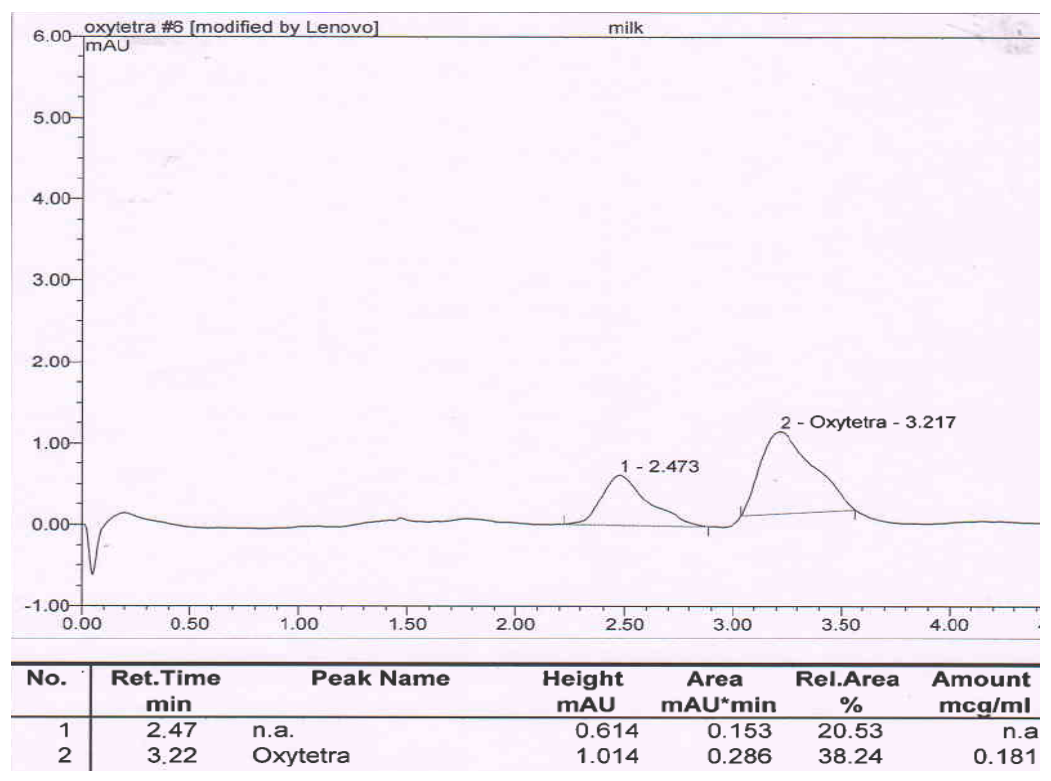

Fig.4 Chromatogram of milk sample of cow detected with TC residue

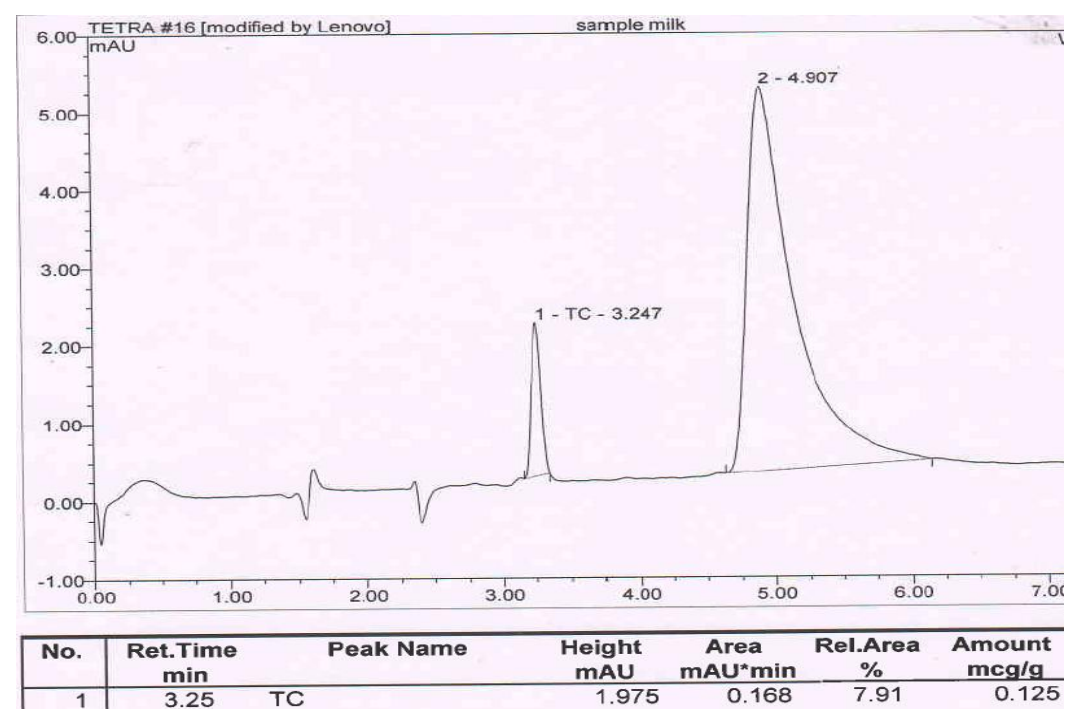

The response of the DAD was linear and highly correlated with the amounts of TC injected, where the calculated coefficient $\left(r^{2}\right)$ ranged from 0.991 to 0.995 and each TCs had own linear equation. The sensitivity of the method is usually represented by the slope of the analytical calibration curve. Accuracy and recovery was in the range of $95.0-99.0 \%$ and 91.5-98.0\% for OTC and TC in milk indicating that the method can be used as a validated method. Earlier, a method was reported where recovery of TC was $70 \%$ using a reverse phase HPLC method with diode array detection for the determination of tetracycline residue in milk $^{[10]}$.

OTC residue was detected in 2 milk samples of Cow with concentration of $0.146 \mu \mathrm{g} / \mathrm{g}$ and $0.181 \mu \mathrm{g} / \mathrm{g}$. Both the samples were above the MRL. Also, 3 samples of Cow milk were 
detected with residues of TC with level of $0.083 \mu \mathrm{g} / \mathrm{g}, 0.114 \mu \mathrm{g} / \mathrm{g}$ and $0.125 \mu \mathrm{g} / \mathrm{g}$. Out of the 3 samples, 2 samples were found to be above the MRL. Similar finding was reported by Jevinova et al., (2003) where OTC residues above the MRL were detected in milk samples of cow of Slovakia ${ }^{[6]}$.Seyda and Ayhan (2010) screened 240 samples of milk for determination of antibiotic residues including OTC using TLC ${ }^{[11]}$. But only $1.14 \%$ and $1.71 \%$ of the samples were found to be positive of OTC and TC residue which shows that the antibacterial agents may not be indiscriminately used in the state of Assam.

In conclusion, the present method reliably identifies and quantifies the selected TC and OTC in the reconstituted milk samples in very low range which can be applied for monitoring purpose. Since about $1 \%$ of the milk samples were positive of OTC and TC residue it may be assumed that the drugs for now are not in indiscriminate use in the state of Assam. But time to time monitoring is recommended for public health concern.

\section{Acknowledgment}

The authors acknowledges the help receive from ICAR and AAU, Jorhat.

\section{References}

1. Cinquina, AL, Longo F, Anastasi G, Giannetti L, Cozzani R. Validation of a high-performance liquid chromatography method for the determination of oxytetracycline, tetracycline, chlortetracycline and doxycline in bovine milk and muscle. J Chromatogr. A. 2003; 987:227-33.

2. Blanchflower, W.J, McCracken R.J, Haggan A.S, Kennedy D.G. Confirmatory assay for the determination of tetracycline, oxytetracycline, chlortetracycline and its isomers in muscle and kidney using liquid chromatography-mass spectrometry. J Chromatogr. B Biomed Sci Appl.1997; 692: 351-60.

3. Michalova, E., Novotna, P. and Schlegelova, J. Tetracyclines in veterinary medicine and bacterial resistance to them. Veterinary Medicine Czech, 2004; 49: 79-100.

4. Nouws, JFM, Loeffen G, Schouten J, Van Egmond H, Keukens H, Stegeman H. Testing of raw milk for tetracycline residues. J Dairy Sci. 1998; 81(9): 2341-2345

5. Treetepvijit, S, Preechaworapun A, Praphairaksit N, Chuanuwatanakul S, Einaga Y, Chailapakul O. Use of nickel implanted boron-doped diamond thin film electrode coupled to HPLC system for the determination of tetracyclines. Talanta. 2006; 68:13291335.

6. Jevinova, P., Dudrikova, E., Sokol, J., Nagy, J., Mate, D., Pipova, M. and Cabadaj, R.. Determination of Oxytetracycline residues in milk with the use of HPLC method and two microbial inhibition assays. Bulletin Veterinary Inst Pulawy, 2003; 47:211216.

7. Navratilova, P., Borkovcova, I., Drackova, M., Janstova, B. and Vorlova, L. Occurrence of Tetracycline, Chlortetracycline and Oxytetracycline residues in raw cow's milk. Czech Journal of Food Science, 2009; 27: 379-385.

8. Bilandzic, N., Kolanovic, B.S., Varenina I. and Jurkovic $Z$. Concentrations of veterinary drug residues in milk from individual farms in Croatia, Mljekarstvo, 2011; 61(3): 260-267

9. Furusaw N. Rapid liquid chromatographic determination of oxytetracycline in milk. J Chromatogr. A. 1999; 839:247-51. 
10. Elizabeta, D.S., Zehra, H.M., Biljana, S. D., Pavle, S. and Risto U. (2011) Screening of veterinary drug residues in milk from individual farms in Macedonia. Mac. Vet. Rev., 2011; 34 (1):5-13.
11. Seyda, E.K. and Ayhan, F. Determination of antibiotic residues in milk samples. Kafkas Univ Vet Fak Derg, 2010; 16: $31-35$

\section{How to cite this article:}

Rajkishor Gogoi and Roy, D.C. 2019. Screening of Raw Milk Samples of Cow for Tetracycline Residues using Chromatographic Technique Int.J.Curr.Microbiol.App.Sci. 8(04): 1482-1488. doi: https://doi.org/10.20546/ijcmas.2019.804.173 